\title{
Formação de professor e história oral: narrativas e algumas (im)possibilidades metodológicas
}

\author{
Teacher education and oral history: narratives and some \\ methodological (im)possibilities
}

\section{Formación docente e historia oral: narraciones y algunas posibilidades (im)metodológicas}

\author{
Rosemeiry de Castro Prado' \\ Faculdade de Tecnologia do Estado de São Paulo, Professora associada. \\ http://orcid.org/0000-0002-6541-1607 \\ Kátia Guerchi Gonzales² \\ Universidade Estadual de Mato Grosso do Sul, Universidade Anhanguera Uniderp, Professora. \\ https://orcid.org/0000-0003-2827-2545
}

Resumo: Este trabalho é um exercício do que tem sido chamado, nas investigações do Grupo de "História Oral e Educação Matemática" (GHOEM), de metodologia em trajetória, isto é, o modo como, ao desenvolver um trabalho específico, questões de natureza metodológica surgem e podem/ devem ser tematizadas pelo pesquisador como parte de sua pesquisa que, assim, contribui para o arcabouço metodológico de todo o seu grupo. No caso, a pesquisa em questão trata de um estudo das Faculdades de Tecnologia (FATECs) do Estado de São Paulo e se inscreve no projeto do GHOEM chamado "Mapeamento da formação e atuação de professores que ensinam/ensinaram Matemática no Brasil". Destarte, este artigo apresenta uma breve síntese de alguns trabalhos já desenvolvidos nesse Projeto de Mapeamento, localizando nele, especificamente, a pesquisa sobre a FATEC para, em seguida, tendo como exemplo uma entrevista realizada para esta investigação, problematizar um aspecto metodológico do trabalho com narrativas, apontando algumas de suas possíveis fragilidades e potencialidades.

Palavras-chave: Narrativas. Entrevistas. Formação de professores. Metodologias de Pesquisa. História da Educação Matemática.

Doutora em Educação para a Ciência pela Universidade Estadual Paulista Júlio de Mesquita Filho; Mestre em Educação Matemática pela Pontifícia Universidade Católica de São Paulo.

2 Doutora em Educação para a Ciência pela Universidade Estadual Paulista Júlio de Mesquita Filho; Mestre em Educação Matemática pela Universidade Federal do Mato Grosso do Sul. 
Abstract: This work is an exercise of what has been called, in the investigations of the Group of "Oral History and Mathematical Education" (GHOEM) of methodology on the trajectory, that is, how, in developing a specific work, questions of methodological nature arise and can/should be thematicised by the researcher as part of his research, which thus contributes to the methodological framework of his whole group. In this case, the research in question is a study of the Faculties of Technology (FATECS) of the State of São Paulo, and is part of the GHOEM project, called "Mapping of the training and performance of teachers who teach/teach mathematics in Brazil". Thus, this article presents a brief synthesis of some works already developed in this Mapping Project, locating in it, specifically, the research on FATEC, then, having as example an interview conducted for this research, problematize a methodological aspect of the work with narratives, pointing out some of its possible fragilities and potentialities.

Keywords: Narratives. Interviews. Teacher training. Research Methodologies. History of Mathematics Education.

Resumen: Este trabajo es un ejercicio de lo que se ha llamado, en las investigaciones del Grupo de "Historia Oral y Educación Matemática" (GHOEM) de metodología en trayectoria, es decir, cómo evoluciona un trabajo específico, cuestiones de naturaleza metodológica surgen y pueden/deben ser tematizadas por el investigador como parte de su investigación que, así, contribuye al marco metodológico de todo su grupo. En el caso, la investigación en cuestión trata de un estudio de las Facultades de Tecnología (FATEC) del Estado de São Paulo, y se inscribe en el proyecto del GHOEM, llamado "Mapeamiento de la formación y actuación de profesores que enseñan/enseñaron Matemáticas en Brasil". De este modo, este artículo presenta una breve síntesis de algunos trabajos ya desarrollados en ese Proyecto de Mapeo, localizando en él específicamente la investigación sobre la FATEC para, a continuación, teniendo como ejemplo una entrevista realizada para esa investigación, problematizar un aspecto metodológico del trabajo con narrativas, apuntando algunas de sus posibles fragilidades y potencialidades.

Palabras clave: Narrativas. Entrevistas. Formación de profesores. Metodologías de Investigación. Historia de la Educación Matemática.

Recebido em 28 de dezembro de 2018 Aceito em 7 de dezembro de 2019

Publicado em 19 de junho de 2020

\section{INTRODUÇÃO}

Este trabalho é resultado de um texto cujo intuito foi discorrer sobre a formação de professores. Tal texto foi produzido como resultado final da disciplina intitulada História da Educação Matemática, oferecida no Programa de Pós-graduação de Educação para Ciência da 
Universidade Estadual Paulista Júlio de Mesquita Filho (Unesp-Bauru), que teve como objetivo principal discutir, de um ponto de vista teórico-filosófico, metodologias e elementos da História da Educação Matemática.

Durante as aulas, assuntos como História da Educação Matemática, Formação de Professores, produção e utilização de narrativas em pesquisas, além da Hermenêutica de Profundidade atrelada às fontes de pesquisa permearam e fomentaram as discussões.

Vários trabalhos foram estudados, destacando modos diferenciados de formação de professores, como, por exemplo, a Campanha de Aperfeiçoamento e Difusão do Ensino Secundário (CADES), o Projeto Ipê, o Serviço de Orientação Pedagógica (Serop), o Centro de Ensino de Ciências (Cecís), o Projeto Minerva e as Licenciaturas Parceladas. Via de regra, essas modalidades de formação mostram historicamente a carência e a urgência da política educacional em termos de formação de professores. Como pano de fundo das discussões, narrativas que compuseram outros trabalhos e que perpassavam por questões de interesse da disciplina foram apresentadas em forma de seminários, tornando-se o fio condutor de apropriações.

Elemento fundamental dos trabalhos do Grupo "História Oral e Educação Matemática" (GHOEM), que lança mão da metodologia da História Oral (HO) na constituição de fontes históricas, as narrativas exploram a oralidade, ou seja, a partir das entrevistas dispara-se um conjunto de ações - embora a HO não se reduza a esse conjunto - com procedimentos relativamente estáveis para o desenvolvimento das investigações (GARNICA; FERNANDES; SILVA, 2011; MARTINS-SALANDIM, 2012; MORAIS, 2012), envolvendo a elaboração de roteiros, a entrevista, a transcrição, a textualização e a validação da entrevista por meio da carta de cessão.

Destarte, durante as discussões sobre outros modos de produzir entrevistas apontou-se a possibilidade de se entrevistar assincronicamente, via e-mail, com um roteiro previamente elaborado e enviado ao colaborador, de modo distinto ao que se trabalha no grupo, ou seja, sincronicamente e via oral, de modo a permitir reflexões, conjecturas e discussões sobre a importância da experiência em narrar e, consequentemente, das narrativas.

\section{FORMAÇÃO DE PROFESSORES: UM MAPA DINÂMICO E EM CONSTANTE CONSTRUÇÃO}

Adotando-se uma perspectiva que considera estudos realizados na linha temática que se debruça nas questões sobre a história da formação e atuação dos professores de Matemática, as Faculdades de Tecnologia do Estado de São Paulo são exemplo de uma 
investigação que, recentemente, se inscreve no mapeamento proposto pelo Grupo de "História Oral e Educação Matemática" (GHOEM) sobre a formação de professores de Matemática no Brasil.

Constituído por pesquisadores, professores e alunos de graduação e pósgraduação, o GHOEM assume uma característica singular quanto aos processos de investigação e análise de dados, contemplando a gravação de depoimentos de pessoas envolvidas de forma direta ou indireta com a Educação Matemática, visando atender aos seus vários temas de pesquisa. Um dos projetos de amplo espectro desse grupo é o que tem como título "Mapeamento de formação e atuação de professores de Matemática no Brasil".

Para se investigarem os aspectos e modos de atuação desses professores nas diversas regiões em que atuaram/atuam, bem como as características socioculturais em diversos lugares e momentos, o "Mapeamento tornou-se um projeto que continuamente se faz projeto e a cada esforço cotidiano vai assumindo mais e mais feições do grupo que o sustenta." (GARNICA, 2014, p. 64). Iniciado no ano de 2000, ele é uma iniciativa "necessariamente coletiva, e não visa apenas produzir estudos sobre um tema, mas, também, a ser um artifício de formação de pesquisadores em educação Matemática." (GARNICA, 2014, p. 49).

\footnotetext{
[...] Mapear - ou cartografar - a formação e a prática de professores de Matemática, portanto, é um projeto dinâmico que, se permite compreensões, por exemplo, por cotejamentos (sempre parciais) entre instâncias de formação, instituições formadoras, modos de atender ou subverter legislações, etc., também permite que o leitor se perca, pois nunca $\circ$ mapeado estará configurado de forma definitiva de modo a brandamente submeter-se aos cotejamentos que talvez seu leitor quisesse realizar [...] (GARNICA, 2014, p. 42).
}

Contudo, a concepção do mapa que norteia o GHOEM é diferente daquela tradicionalmente concebida, indo além do "conjunto de estudos e operações científicas, técnicas e artísticas que orientam os trabalhos de elaboração de cartas cartográficas" (HOUAISS; VILLAR, 2001) ou da "arte ou ciência de compor cartas geográficas." (FERREIRA, 2004). Além se ser um mapeamento histórico, ele é assumidamente incompleto, ímpar, composto por desenhos que ainda não foram nem serão terminados. É dinâmico, aberto e múltiplo, diverso, disforme, mas permite compreensões (GARNICA, 2014).

Muitos desenhos já foram realizados e compõem o mapa atual desenhado por um grupo que se propõe a criar ações que tanto orientem quanto desorientem, mas, acima de tudo, propõe-se a registrar as transformações nas paisagens da formação e atuação dos professores de Matemática no nosso País. 
Em Martins (2003) é apresentado um trabalho de iniciação científica no qual a autora faz um registro histórico da formação e atuação de professores de escolas rurais da região de Bauru, SP, nas décadas de 1950 e 1960. Além de caracterizar particularidades de um tipo de escola de ensino primário que oferecia apenas as três primeiras séries de forma multisseriada, com apenas um professor para atender a todas as crianças, a pesquisa retratou as dificuldades encontradas pelos alunos campesinos e pelos professores que atuaram na zona rural. A zona rural foi, então, caracterizada pela autora como "zona de passagem", já que os professores permaneciam pouco tempo nelas por buscarem, na zona urbana, sempre mais facilidades e melhores condições. Posteriormente, e dando continuidade ao mapa produzido pelo GHOEM, Martins-Salandim (2007) dedicou-se, em seu mestrado, a pesquisar a formação e atuação de professores em um tipo específico de escola - a de ensino técnico agrícola, no interior paulista. 0 cenário estudado serviu como palco de investigação em História da Educação Matemática em particular e, de um modo geral, para a compreensão dos papéis que as instituições desempenharam ao longo da história educacional do País, bem como as condições de marginalidade e o assistencialismo que caracterizavam essas escolas técnicas que, de algum modo, estendiam a situação das escolas campesinas já estudadas pela mesma autora.

A questão da igualdade de condições versus a desigualdade de oportunidades que surge vinculada ao ensino agrícola e às escolas rurais também se manifestou em Martins-Salandim (2012), pesquisa de doutorado da autora. Ao focar particularmente a década de 1960, período em que se intensificou o processo de interiorização dos cursos de Matemática pelo Estado de São Paulo, as análises ocorreram em dois diferentes momentos; cada um em uma modalidade distinta: uma de singularidades e outra de convergências. $\mathrm{Na}$ análise de singularidades, a autora destacou suas percepções sobre como as narrativas apresentaram-se, bem como o fio condutor e a perspectiva das falas de cada depoente, registrando indícios que permitiram falar ou pensar sobre os cursos e atores desse cenário de criação e expansão do ensino superior pelo Estado de São Paulo. A análise de singularidades buscou ressaltar as marcas da subjetividade e a importância da história de cada um dos entrevistados.

Fernandes (2011), ao registrar historicamente os processos de formação de professores de Matemática no Estado do Maranhão a partir da década de 1960 (momento em que se implantou o primeiro curso de licenciatura no Estado), busca compreender o movimento de criação e consolidação de cursos de Licenciatura em Matemática em três instituições públicas maranhenses de ensino superior: a Universidade Federal do Maranhão (UFMA), a Universidade Estadual do Maranhão (UEMA) e o então Centro Federal de Educação Tecnológica do Maranhão (CEFET-MA). 
A pesquisa da autora contou com 16 entrevistas cujos colaboradores são pessoas envolvidas no processo de implantação dos primeiros projetos de formação de professores naquele Estado, além de documentos oficiais e projetos pedagógicos de cursos, acabando por revelar a situação marginal na qual se encontrava o Maranhão em relação a outros estados no que diz respeito à educação superior e, particularmente, no que concerne à carência e à urgência da formação de professores de Matemática, uma constante, como já nos referimos, aos trabalhos que têm como tema a formação de professores que ensinam/ ensinaram Matemática no Brasil.

0 livro de Baraldi e Gaertner (2013) também tem colaborado com a compreensão das mudanças ao longo do tempo com relação às concepções de formação de professores no Brasil. Ao fazer um esboço sobre a Campanha de Aperfeiçoamento e Difusão do Ensino Secundário (CADES), criada no Governo de Getúlio Vargas, o texto aborda um período em nosso País em que, visando-se à modernização pela qual passava o Brasil, investiu-se na formação de seus professores secundários, uma vez que era flagrante a expansão desse nível de escolaridade nos anos 1950, sem que, como contrapartida, houvesse professores formados para nele atuarem, com o que se detecta a massiva atuação de professores leigos, cujos saberes docentes se fundavam na prática da carreira do magistério. As autoras perceberam que a CADES, ao longo de sua existência (1953-1971), permitiu que milhares de professores tivessem acesso à formação profissional para atuarem no ensino secundário, principalmente no interior do País. A Campanha conquistou status de órgão, com corpo robusto, que serviu para difundir o ideário educacional e político da época, contando com investimentos federais. A CADES, com seus cursos, exames, periódicos, manuais e publicações diversas, foi essencial para a formação de professores e a consolidação da escola secundária no País. Extinguiuse em decorrência da Lei n. 5.692/71, que ajudou a proliferar as licenciaturas no Brasil e, consequentemente, a necessidade de um "diploma" para "oficializar" a prática docente, culminando na intensificação da "formação" do professor secundário por meio das faculdades.

Vinculam-se também ao contexto da Lei n. 5.692/71 as Licenciaturas Parceladas no Estado do Sul do Mato Grosso (posteriormente Mato Grosso do Sul), que se caracterizam como uma formação emergencial, visando a suprir a carência de professores diplomados naquele Estado, no que se destacam dois momentos cruciais: na década de 1970 e na década de 1990, quando surgiram a Licenciatura Parcelada de Curta Duração em Ciências (na década de 1970) e o curso de Ciências - Habilitação em Matemática, em regime parcelado, previsto no Projeto de Interiorização do Ensino de Graduação (na década de 1990). Os dois projetos tinham como finalidade qualificar professores que já atuavam no ensino básico, mas não tinham formação específica. Assim, um dos principais objetivos era capacitar docentes que atuavam na rede pública de ensino de primeiro e segundo graus, em regime especial, geralmente durante as férias escolares, visando ao melhor atendimento da comunidade sulmato-grossense. Nota-se, portanto, conforme os estudos de Baraldi e Gaertner (2013), que 
nem as licenciaturas existentes nem a CADES conseguiram, no território nacional, suprir as carências que as escolas sofriam quanto à atuação de professores com formação adequada, posto que, ainda na década de 1990, o Mato Grosso do Sul era vitimado pela insuficiência de professores, graduados, em atuação.

Nesse sentido, "elaborar, em configuração aberta, um registro das condições em que ocorreram/ocorrem a formação e atuação de professores de Matemática" (GARNICA; FERNANDES; SILVA, 2011, p. 241) é uma característica presente nas pesquisas realizadas pelo GHOEM, abordando a diversidade e as dimensões históricas, que são elementos essenciais à questão da formação e atuação de professores de Matemática no Brasil (GOMES, 2014, p. 16).

Dando sequência a esse conjunto de estudos que têm como tema modalidades específicas de formação em tempos e espaços diversificados, o mapeamento passa a estudar as Faculdades de Tecnologia do Estado de São Paulo (Fatecs), hoje instituições públicas de ensino superior pertencentes ao Centro Estadual de Educação Tecnológica Paula Souza (Ceeteps), autarquia do Governo do Estado de São Paulo vinculada à Secretaria de Desenvolvimento Econômico, Ciência, Tecnologia e Inovação (SDECTI). Numa época em que, como decorrência dos fatores políticos, decidiu-se pela modernização exigida por um mundo cada vez mais tecnológico. Tratar-se-ia, portanto, de estimular uma matemática que ajudaria - País a se desenvolver científica e tecnologicamente. As Faculdades de Tecnologia surgem nesse contexto, e há, subjacente à história dessas Faculdades, um pensamento educacional geral que atrelou o saber matemático ao saber científico e, dentro desse último, à tecnologia.

A Fatec foi criada pelo Decreto-Lei de 6 de outubro de 1969, na gestão do governador Roberto Costa de Abreu Sodré (1967-1971), como resultado de um grupo de trabalho para avaliar a viabilidade de implantação gradativa de uma rede de cursos superiores de tecnologia com duração de dois e três anos, que tinham por objetivo a formação de técnicos de nível superior para atender à crescente demanda de profissionais de nível universitário. Em 1970, começou a operar com o nome de Centro Estadual de Educação Tecnológica de São Paulo (CEET), com três cursos na área de Construção Civil (Movimento de Terra e Pavimentação, Construção de Obras Hidráulicas e Construção de Edifícios) e dois na área de Mecânica (Desenhista Projetista e Oficinas). Era o início das Faculdades de Tecnologia do Estado. As duas primeiras foram instaladas nos Municípios de Sorocaba e São Paulo.

Para nosso projeto de doutoramento, cujo tema central é a Fatec e os professores de Matemática que nela atuavam, entrevistas estão sendo realizadas. Nelas têm sido abordadas questões que perpassam a formação e atuação dos docentes de matemática dessas instituições. Vale ressaltar que pouco ainda se sabe sobre a história desses professores em suas faculdades, o que dificulta - quando não impede - a reflexão e a ação e mudança coletiva no desenvolvimento institucional (BOLÍVAR; DOMINGO; FERNÁNDEZ, 2001). Ao se compreenderem elementos relevantes do entorno dos professores de matemática das 
faculdades de tecnologia poder-se-á contribuir para o entendimento dos diversos interesses vinculados ao ensino da matemática nas Fatecs.

\section{AS NARRATIUAS: EXPERIÊNCIAS QUE POSSIBILITAM RELATOS UIUIFICADOS}

Uma inquietação provocada durante a disciplina História da Educação Matemática possibilitou um crivo investigativo: "como seria a mesma entrevista, baseada no mesmo roteiro, com o mesmo entrevistado, se feita segundo outro procedimento que não o orall" $\mathrm{Ou}$, de outro modo, "realmente existiram diferenças qualitativas nos distintos procedimentos usados para se fazer entrevistas, mostrando potencialidades e fragilidades que, aparentes numa forma de ação, outras formas impediriam ou dificultariam?". Trata-se, portanto, de uma questão do domínio da metodologia. Tal é a natureza do que temos chamado de "metodologia em trajetória", ou seja, a potencialidade de questionar elementos da metodologia não antes, mas durante o desenvolvimento de pesquisas específicas. Adotamos neste trabalho o mesmo conceito de potencialidade utilizado por Tizzo (2014), o qual compreende o termo em seu sentido amplo, ou seja, como característica daquilo que está em potência, que contém a possibilidade de vir a ser algo e, desse modo, consequentemente, poderá resultar em um evento de sucesso (ou não), apresentando fragilidades ou aspectos relevantes e singulares.

Essa questão metodológica específica foi por nós tematizada num exercício: depois de termos realizado a entrevista com um de nossos colaboradores, enviamos, ao mesmo colaborador, via e-mail, as perguntas contidas no roteiro original que havíamos seguido quando da primeira entrevista. No momento em que a entrevista foi respondida por e-mail, percebemos a possibilidade de um exercício que nos pareceu importante para os desenhos metodológicos que nos propomos a realizar: uma comparação entre as duas entrevistas poderia ser traçada. Investindo nessa possibilidade, duas das perguntas realizadas nas entrevistas com o professor foram selecionadas aleatoriamente e tematizadas a partir de aspectos que, como temos discutido, permeiam a metodologia da História Oral.

A entrevista realizada oralmente (a primeira entrevista) teve duração de 57'13" e ocorreu no dia 16 de março de 2016 (gerando 12 páginas de transcrição) com um professor da Fatec Ourinhos. Uma semana depois, o mesmo roteiro usado anteriormente foi enviado por e-mail ao professor que, após responder às perguntas, as imprimiu e nos entregou uma cópia contendo três páginas, com as perguntas e respostas. Dois recortes dessas duas ações distintas vêm apresentados a seguir, sendo as perguntas e as respostas obtidas no primeiro momento, da entrevista oral, indicadas por A, e as pautadas por e-mail indicadas por B: 
Formação e atuação profissional do depoente:

(A) “Eu nasci em Manaus, Amazonas, em 29 de janeiro de 1951. De lá eu vim para São Paulo com oito anos de idade, porque eu tenho um irmão que é oito anos mais velho, e em Manaus, na época, não havia nenhum curso de graduação. 0 máximo que você tinha era um curso de Direito, então as famílias migravam muito por conta dos filhos. Então, nós viemos pra São Paulo e depois nunca mais voltei. Fiquei em São Paulo durante 27 anos e morei em Bauru durante quatro anos, e em Ourinhos eu já estou há 20, 25 anos. Quanto a minha formação, prestei vestibular na época, em 1969, para engenharia eletrônica e para matemática. A princípio, eu cursava as duas faculdades e ainda trabalhava para sustentar as obrigações, os pagamentos. E aí, é claro, eu não aguentei. Eu tive que abandonar uma das faculdades; eu optei por matemática e abandonei a engenharia de que, realmente, eu tinha uma outra visão a respeito; não a ideia da engenharia teórica. Pra mim, a engenharia era bem mais prática do que é. E aí eu fiquei com a matemática e comecei muito cedo a dar aula em cursinho. $\mathrm{Na}$ época estava começando essa febre de cursinhos, então tinha alguns cursinhos iniciando, não existia ainda o Objetivo; tinha em São Paulo o Anglo, que era o mais tradicional, e tinha - Diágoras, Diágoras Cultural, que ficava na Praça da Liberdade, um prédio de oito andares, e pra época eles tinham mais de 1.500 alunos. Quer dizer, então já era um curso pesado. E eu comecei a dar aula nesse cursinho com 20 anos de idade. E, dali, nunca mais parei, eu dei aula em cursinho até 1986, quer dizer, durante uns 16 anos eu dei aula em cursinho. Mas eu sempre, em paralelo, tinha outras atividades, e a minha atividade paralela era trabalhar com informática. E à medida que a informática foi se concretizando na minha vida, foi se tornando prioritária, mais importante. Teve uma época que eu tive que abandonar o cursinho, porque eu não dava mais conta. Trabalhava de oito a 10 horas por dia com informática e cheguei a ser gerente de um centro de processamento de dados com 38 funcionários. $E$ então, no cursinho eu dava aula de fim de semana, sábado, mas mesmo assim me cansava muito, abandonando-o. A engenharia eu fazia na FEl, que na época era da PUC. Ela estava começando em São Bernardo. Não tinha se mudado totalmente para São Bernardo, mas, de qualquer forma, eu como calouro em 1969, já ia até São Bernardo. Isso era um desgaste porque era uma viagem grande de ônibus. E a matemática eu fazia na faculdade Oswaldo Cruz. E, aliás, foi interessante porque, quando eu terminei a matemática, o diretor na época, que era o Professor Damato, me convidou para ser auxiliar de docência na faculdade, então a minha carreira na faculdade começou ali. E aí eu comecei a dar aula na Faculdade, junto com o cursinho, e junto com informática. Quer dizer, então eu já tava com 23 anos de idade... Não, menos, 22. No cursinho, eu comecei com 20 anos. Passei para o segundo ano da faculdade de matemática, e aí eu prestei concurso, tinha uma vaga para professor lá no Diágoras, e aí tinha lá uns 20 candidatos, a gente teve que dar uma aula, sorteava um ponto e dava uma aula. Eu até me lembro até hoje que o meu ponto sorteado foi matrizes, determinantes e sistemas lineares. E aí eu dei uma aula sobre isso, e aí a banca fez uma série de questionamentos 
e tal, aí no fim eu fui o aprovado. Eu abandonei o cursinho numa época onde eu tinha mais responsabilidades, mas o abandonar era assim, eu tinha uma aula, por exemplo, de fim de semana, ou então eu dava um cursinho de férias, ou então... eu nunca parei de dar aula. Aí, quando eu abandonei a informática, quer dizer, eu também me cansei porque era muito desgastante, muita responsabilidade, eu resolvi prestar um concurso na Fatec, para ficar um pouco mais definitivo na Fatec. E aí eu fui aprovado nesse concurso. Isso foi em 1986. 0 meu mestrado eu fiz na USP, até por conta do quê? 0 Centro Paula Souza fez um convênio com a USP de fazer um mestrado voltado para os professores, um grupo de professores do Centro Paula Souza. Então foram 20 e poucos professores, acho que 24 professores de várias Fatecs, quer dizer, tinha professores de Americana, de Sorocaba, de São Paulo, de Ourinhos, e esses professores tiveram um curso sendo desenvolvido na Fatec Jaú, que era, vamos dizer, entendido, que a Fatec que ficaria mais próxima para todo mundo e tal, para não ter que deslocar muita gente até São Paulo. Então, o meu tema foi curvas B-Spline, para confecção de cascos de navios. Na realidade a ideia foi desenvolver um software, que permitia ao projetista, vamos dizer, brincar com o casco do navio através de curvas B-Spline, e nessa brincadeira, nessa tentativa de fazer um acerto no casco, o software iria calculando todos os coeficientes importantes para a boa navegação. Então, têm coeficientes assim, coeficiente prismático, coeficiente de calado, são várias coisas que a engenharia naval define como sendo boas, e o software fazia assim, a cada movimento que você fazia com o mouse e modificada um pouco a curva, ele mostrava pra você o que implicava isso nos coeficientes todos, do que a engenharia naval definia como coeficientes bons, e tal. Então era um software voltado para o engenheiro projetista, para projetar um casco de navio utilizando as curvas B-Spline. Eu acabei fazendo o mestrado porque teve uma época que corria à boca pequena que os professores não titulados seriam extintos. Quer dizer, eles ficariam numa carreira em extinção, e dentro dessa carreira não haveria mais nenhum tipo de aumento, e eles ficariam até pedir para sair. Então com essa possibilidade, isso aconteceu em 1999, quando se colocou que seria assim, que haveria esse problema, então eu achei melhor correr atrás do prejuízo e fazer um mestrado, coisa que eu nunca tinha me interessado. E acabei fazendo e terminei o meu mestrado em 2003." (informação verbal).

(B) “Básica: São Paulo/SP, 1965-1968, Colégio Oswaldo Cruz; Universitária: São Paulo/ SP, 1969-1972, Faculdade de Filosofia Ciências e Letras, Colégio Oswaldo Cruz; Pós-Graduação: São Paulo/SP, 2001-2003, Universidade de São Paulo (POLI). Graduação em Matemática, cursos de especialização em Informática e experiência profissional na área de Informática. Professor de cursinho, programador de computador, analista de sistemas, vice-chefe de departamento, gerente de centro de informática, professor da Fatec, membro do Conselho Deliberativo do Centro Paula Souza." (informação verbal).

À primeira vista, as informações obtidas nos itens $A$ e $B$, relativas à pergunta sobre afirmação e atuação profissional do depoente, impressionam pela diferença nos textos 
de resposta. 0 texto $A$ parece traduzir com mais detalhamento e vivacidade a subjetividade e a emoção que o entrevistado coloca em sua resposta, ao passo que o modo sucinto, telegráfico com que ele responde a mesma questão, em B, pode ser caracterizado como uma outra e distinta resposta que, mesmo nos apontando alguns elementos para análise, perde em densidade no que diz respeito ao modo de relatar a própria experiência. 0 relato vivificado em A nos aproxima mais de uma linguagem da experiência, uma experiência que se elaborou na forma de relato, que é matéria-prima do relato. Talvez, por isso, se o relato desaparece, se se transforma numa sequência de informações sem trama, desaparece também a língua com a qual se elaboram e se trocam as experiências; desaparece, tendencialmente, no fundo, a própria possibilidade de elaborar e trocar experiências (BENJAMMM, 1994).

A narrativa em A não se limita a meramente transmitir uma informação ou uma listagem de informações: ela mergulha o narrado na vida do narrador para comunicar algo com as marcas do colaborador que se reconstitui e se percebe como sujeito da sua história. Não se trata de menosprezar as informações obtidas em $B$, mesmo porque a partir delas surgem novas possibilidades de entendimentos, trata-se de perceber a possibilidade de se dizer alguma coisa a mais, via processos distintos, e também perceber que o discurso, a natureza do relato, é sempre único, disparando um sentido qualitativo da informação, não meramente uma informação "em si". Não se trata de conceber a potencialidade da História Oral como sinônimo de autossuficiência dos fatos orais em relação a outras fontes, mas reconhecer que a natureza qualitativa dessas informações pode trazer contribuições à historiografia. Fontes de naturezas diferentes trazem versões e possibilidades distintas.

A chegada à Fatec e as aulas ministradas:

(A) "Foi até gozado, porque quem me convidou, quem me disse do concurso, foram três professores que eram meus colegas no Diágoras Cultural. Nós tínhamos dado aula juntos em 1970, 71, e 72. E esses três professores, eles foram fundadores da Fatec São Paulo. Eles estiveram na Fatec de São Paulo desde o início. E aí, em 1986, que foi quando eu resolvi fazer alguma coisa mais voltada para a carreira de matemática, eles é que me convidaram. Eles já estavam bem consolidados na Fatec, era o grupo de professores da Fatec São Paulo, aliás, brilhantes professores, excelentes. Era o Walter Paulette, Santo Scuderi e Ayrton Barboni. Eram os três que eram meus colegas do Diágoras, e dois deles fizeram parte da minha banca. Quer dizer, eles já tinham feito parte da minha banca quando eu entrei no Diágoras. Então, esse concurso que eu prestei, na realidade, ele foi para a área de informática. Não foi para a matemática. E foi para a área de informática por quê? Porque a demanda por informática era muito grande na época e existiam poucos profissionais no mercado. Então, não havia a necessidade de ser formado em informática, ter um diploma em informática. A minha experiência - eu já tinha sido até gerente de um centro de processamento de dados - contou muito ponto, uma pontuação muito alta, pelo fato de eu trabalhar na área já por 
mais de 15 anos. Então essa experiência foi fundamental. E eu tinha o diploma de graduação em matemática, que era considerada disciplina afim. Então eu prestei o concurso e me lembro bem que foi um concurso para dar aula de entrada de dados, e que na época entrada de dados era feita por cartão perfurado e tal, então eu ensinava os alunos quais eram as possibilidades de entrar com dados dentro do computador, algumas fitas magnéticas, cartões perfurados e tal. E como essa disciplina veio a se extinguir, quer dizer, depois de um certo tempo não tinha mais essa disciplina, eu fui migrando, e numa das migrações que eu fiz eu fui para matemática. Isso já foi na Fatec São Paulo. Então, quando eu vim para Ourinhos, eu já vim dando aula de informática e matemática, eu dava as duas disciplinas. Então, a matemática inicialmente era extremamente pesada, até porque esse grupo de que eu falei que era o Santo, Osvaldo... Santo, Walter Paulette, e o Ayrton, eles eram extremamente dedicados... É... a Fatec São Paulo, quando ela começou, já existia uma biblioteca só para os matemáticos. Tinha uma biblioteca geral, e esse grupo de matemática tinha uma biblioteca própria, só para poder ter acesso a tudo o que tinha de mais atual, tudo o que tinha de mais moderno. Até quando eu entrei para dar aula eu fiquei impressionado com a biblioteca de matemática que existia dentro da Fatec São Paulo. Isso depois foi extinto, o curso foi perdendo esse rigor que tinha de matemática, e foi se reduzindo, até porque, por conta da vida de alunos com muitos problemas, veja que na época não era, na época os alunos vinham bem preparados, eram alunos que tinham feito um bom ensino, um ensino médio público, que era o melhor. № primeiro ano de matemática se via limite, derivada, cálculo integral e se chegava a equações diferenciais. Quer dizer, coisa que hoje nem pensar. Quer dizer, hoje, olha, hoje eu diria que o curso de matemática foi reduzido a uns $10 \%$ do que já foi o curso de matemática dentro das Fatecs." (informação verbal).

(B) “Ano de contratação: 1986; regime de contratação: CLT - concurso público e por tempo indeterminado; tempo de atuação: 30 anos; disciplinas que lecionou ou leciona: Entrada de Dados, Programação em FORTRAN, C, C++, PASCAL e COBOL, Inteligência Artificial, Cálculo, Matemática Discreta, Pesquisa Operacional, Informática Básica. No início de minha contratação a grade curricular de matemática era pesada, pois no seu conteúdo tínhamos limites, derivadas, integrais e uma introdução a equações diferenciais. Com o passar do tempo esse conteúdo foi reduzido, chegando, hoje, ao mínimo necessário para a formação do profissional de uma determinada área. Hoje, vejo que a ênfase maior do curso é na tentativa de recuperar conteúdos da Matemática dos Ensinos Fundamental e Médio." (informação verbal).

Mais uma vez, comparando os textos das respostas $A$ e B, parece-nos que em $A$ o processo de assimilação das narrativas está vinculado à naturalidade com que o narrador renuncia a um modo de contar que esconde as nuances psicológicas, não renunciando à importância das circunstâncias, dos acasos, do imprevisível. Toda trama construída no entorno da chegada do professor à Fatec manifesta-se num relato do que ele criou e vivificou, permitindo que o ouvinte acompanhe esse relato vivo e se torne interlocutor; também ele 
afetado pelos acontecimentos e por seus reflexos e decorrências. Além disso, as experiências pelas quais passou o narrador dão, na versão $A$, um retrato privilegiado, para o entrevistador, de como o entrevistado tratou de dar sentido narrativo ao que viveu, tornando-o sujeito da experiência, personagem dessa trama de sentidos e de sem-sentidos que construiu sua vida (LARROSA, 2014).

A nós parece que as narrativas orais - como Bosi (1992, p. 92) dizia das datas são "pontas de icebergs" que trazem vestígios de elementos do passado que se encontram submersos, mas que podem vir à tona disparando possibilidades e vivificações nas quais "o pretérito passa a existir, de novo." Nunca teremos, nem pelas narrativas nem por qualquer outra fonte, acesso à experiência como experienciada, aos chamados "fatos", mas as narrativas orais podem nos dar uma nova versão, vivida e vívida, do que aconteceu segundo a perspectiva de quem viveu certa experiência. Nenhum relato conseguirá recuperar o passado tal qual ele foi; o passado conhecido é um artefato produzido, no presente, pelo homem, numa trama de significados atribuídos que comunicamos. Optar pelas narrativas ao conduzir uma pesquisa é optar pela tentativa de dar sentido a essas várias e variadas experiências que nossos colaboradores nos contam de muitos modos.

\section{CONSIDERAÇÕES FINAIS}

Este trabalho abordou uma entrevista que, dentre vários aspectos, permeou a formação e a atuação de um professor de matemática no decorrer de sua trajetória docente. Questões arraigadas à compreensão da narrativa do entrevistado possibilitaram disparos importantes com relação às metodologias abordadas e suas potencialidades. Desse modo, as inquietações acerca das possíveis possibilidades e fragilidades de entrevistas síncronas (por meio da oralidade) ou de modo assíncrono (via escrita) permitiram-nos exercitar a construção de uma metodologia em trajetória, problematizando os métodos adotados.

Nas entrevistas síncronas, via oral, podemos destacar que houve presença de subjetivações nas experiências relatadas, uma vez que o sujeito se constitui enquanto narra e para quem narra. Essa constituição do sujeito narrador é natural e espontânea, o roteiro norteia o entrevistado e o entrevistador, mas o entre vistas é que permite múltiplas possibilidades de conexões e/ou rupturas. É nesse contexto que o entrevistado se sente à vontade para salientar detalhes que gostaria de frisar e tecer rotas de fugas quando busca algo ocultar.

As entrevistas assíncronas mostram-se viáveis, contudo há necessidade de estudos mais aprofundados que visem à compreensão da forma como os colaboradores 
interagem com o roteiro para contar sobre sua experiência para um determinado sujeito que questiona - o entrevistador. A partir desse pequeno exercício, há de se destacar que a entrevista feita assincronicamente pode, muitas vezes, limitar-se a transmitir uma determinada informação ou uma lista de acontecimentos. Contudo, tal escolha metodológica pode permitir outros questionamentos e outra possibilidade para a produção de significados àquilo que se pretende entender.

Podemos concluir que as entrevistas assíncronas, via escrita, possam requerer a elaboração e construção de um roteiro, talvez mais interativo, com o intuito de uma apresentação que promova um modelo mais colaborativo e que não comprometa a fluidez das respostas dos entrevistados. Destarte, sugerimos esse exercício para futuras pesquisas ou pesquisadores que tenham como foco a experiência do sujeito e a constituição de narrativas.

\section{REFERÊNCIAS}

BARALDI, l.; GAERTNER, R. Textos e contextos: um esboço da CADES na história da educação (matemática). 1. ed. Blumenau: Edifurb, 2013.

BENJAMIN, W. 0 narrador. Considerações obre a obra de Nikolai Leskov. In: BENJAMIN, W. Magia e técnica, arte e política: ensaios sobre literatura e história da cultura. São Paulo: Brasiliense, 1994. p. 197-221.

BOLIIVAR, A.; DOMINGO, J.; FERNÁNDEZ, M. La investigación biográfico-narrativa em educación: enfoque y metodologia. Madrid: La Muralla, 2001.

BOSI, A. 0 tempo e os tempos. In: NOVAES, A. (org.). Tempo e história. São Paulo: Cia. das Letras, 1992, p. $19-32$.

FERNANDES, D. N. Sobre a formação do professor de matemática no Maranhão: cartas para uma cartografia possível. 2011. Tese (Doutorado em Educação Matemática) - Instituto de Geociências e Ciências Exatas, Universidade Estadual Paulista, Rio Claro, 2011.

FERREIRA, A. B. H. Novo Dicionário Aurélio da Língua Portuguesa. Curitiba: Editora Positivo/Positivo Informática, 2004.

GARNICA, A. V. M.; FERNANDES, D. M.; SILVA, H. da. Entre a amnésia e a vontade de nada esquecer: notas sobre Regimes de Historicidade e História Oral. Bolema, v. 25, n. 41, p. 213-250, 2011.

GARNICA, A. V. M. Cartografias contemporâneas: mapear a formação de professores de Matemática. In: GARNICA, A. V. M. (org.). Cartografias contemporâneas: mapeando a formação de professores de matemática no Brasil. Curitiba: Appris, 2014. 
GOMES, M. L. M. Formação e atuação de professores de matemática, testemunhos e mapas. In: GARNICA, A. V. M. (org.). Cartografias Contemporâneas: mapeando a formação de professores de matemática no Brasil. Curitiba: Appris, 2014.

HOUAISS, A.; VILLAR, M. S. Dicionário Houaiss da Língua Portuguesa. Rio de Janeiro: Objetiva, 2001.

LARROSA, J. 20 Minutos na fila: sobre experiência, relato e subjetividade em Imre Kertész. Tradução: Filipe Santos Fernandes. Bolema, v. 28, n. 49, p. 717-743, 2014.

MARTINS, M. E. Resgate histórico da formação e atuação de professores de escolas rurais da região de Bauru (SP). 2003. Relatório (Iniciação Científica) - Departamento de Matemática, Universidade Estadual Paulista, Bauru, 2003.

MARTINS-SALANDIM, M. E. A interiorização dos cursos de matemática no estado de São Paulo: um exame da década de 1960. Tese (Doutorado em Educação Matemática) - Instituto de Geociências e Ciências Exatas, Universidade Estadual Paulista, Rio Claro, 2012.

MARTINS-SALANDIM, M. E. Escolas técnicas agrícolas e educação matemática: história, práticas e marginalidade. 2007. Dissertação (Mestrado em Educação Matemática) - Instituto de Geociências e Ciências Exatas, Universidade Estadual Paulista, Rio Claro, 2007.

MORAIS, M. B. Peças de uma história: formação de professores de matemática na região de Mossoró (RN). Dissertação (Mestrado em Educação Matemática) - Instituto de Geociências e Ciências Exatas, Universidade Estadual Paulista, Rio Claro, 2012.

TIZZO, S. V. A história oral como uma abordagem didático-pedagógica na disciplina política educacional brasileira de um curso de licenciatura em matemática. 2014. Dissertação (Mestrado em Educação Matemática) - Instituto de Geociências e Ciências Exatas, Universidade Estadual Paulista, Rio Claro, 2014.

Endereço para correspondência: Rua Ceará, até 799, lado ímpar, Vila Antônio Vendas, Campo Grande, Mato Grosso do Sul, Brasil; profkatiaguerchi@gmail.com

Roteiro, Joaçaba, v. 45, p. 1-16, jan./dez. 2020 I e20067 IEISSN 2177-6059 
